University of Louisville

ThinkIR: The University of Louisville's Institutional Repository

Faculty Scholarship

$2-2011$

\title{
Bidirectional relations of religious orientation and depressive symptoms in adolescents : a short-term longitudinal study.
}

\author{
Patrick Pössel \\ University of Louisville \\ Nina C. Martin \\ Vanderbilt University \\ Judy Garber \\ Vanderbilt University \\ Aaron W. Banister \\ University of Louisville \\ Natalie K. Pickering \\ University of Louisville \\ See next page for additional authors
}

Follow this and additional works at: https://ir.library.louisville.edu/faculty

Part of the Cognitive Psychology Commons, and the Counseling Psychology Commons

Original Publication Information

Pössel, Patrick, Nina C. Martin, Judy Garber, Aaron W. Banister, Natalie K. Pickering and Martin Hautzinger. "Bidirectional Relations of Religious Orientation and Depressive Symptoms in Adolescents: A Short-Term Longitudinal Study." 2011. Psychology of Religion and Spirituality 3(1): 24-38.

This Article is brought to you for free and open access by ThinkIR: The University of Louisville's Institutional Repository. It has been accepted for inclusion in Faculty Scholarship by an authorized administrator of ThinkIR: The University of Louisville's Institutional Repository. For more information, please contact thinkir@louisville.edu. 


\section{Authors}

Patrick Pössel, Nina C. Martin, Judy Garber, Aaron W. Banister, Natalie K. Pickering, and Martin Hautzinger 
Running head: RELIGIOUS ORIENTATION AND DEPRESSIVE SYMPTOMS

Bidirectional Relations of Religious Orientation and Depressive Symptoms in Adolescents: A Short-Term Longitudinal Study

\author{
Patrick Pössel \\ University of Louisville \\ Nina C. Martin, Judy Garber \\ Vanderbilt University \\ Aaron W. Banister, Natalie K. Pickering \\ University of Louisville \\ Martin Hautzinger \\ University of Tübingen
}

\title{
Acknowledgments
}

We would like to thank the adolescents, teachers, and school staff for making this study possible. This research was supported by a grant to Martin Hautzinger and Patrick Pössel from the German Research Foundation. 


\begin{abstract}
Religious orientation can be divided into intrinsic and extrinsic: intrinsically oriented individuals "live their religion," whereas extrinsically oriented individuals practice religion mainly to gain external benefits. In adults, depression has been found to correlate negatively with intrinsic religious orientation and positively with extrinsic orientation. Studies of the relation between religiosity and depression typically have not been longitudinal, conducted with adolescents, controlled for the influence of other factors associated with depression (i.e., negative cognitions), or examined the reverse relation of depression predicting religious orientation. Our four-month longitudinal study of 273 ninth-grade students addressed these issues. Results showed that higher intrinsic religious orientation measured at baseline significantly predicted lower self-reported depressive symptoms four months later, controlling for initial level of depressive symptoms and cognitive style; in contrast, extrinsic orientation and the interaction between religious orientation and life events did not significantly predict later depressive symptoms. Self-reported depressive symptoms, however, did not predict either intrinsic or extrinsic religious orientation four months later. Factors contributing to different findings for adolescents versus adults in the relation between extrinsic religious orientation and depression are suggested.
\end{abstract}

Key words: Religious orientation, depression, adolescents, negative life events, cognitive style. 
Religious orientation and depression 3

\section{Depression and religiosity}

Depression is the fourth leading cause of disease burden, accounting for almost $12 \%$ of disability worldwide (Ustun, Ayuso-Mateos, Chatterji, Mathers, \& Murray, 2004), and is expected to become the second most disabling disorder by 2010. Moreover, the financial burden of depression is immense, with an estimated annual cost of approximately $\$ 83.1$ billion in the United States (Greenberg et al., 2003).

Depression often begins during adolescence, with $15 \%$ to $20 \%$ of youth experiencing at least one depressive episode before age 18 (Costello, Foley, \& Angold, 2006). Early onset of depression (i.e., before age 20) is associated with increased risk of recurrence during adulthood (Weissman et al., 1999) as well as the occurrence of other psychiatric disorders (Kasen et al., 2001). Depressive symptoms and disorders in adolescents are associated with academic failure, interpersonal problems, substance abuse, and suicide (Birmaher et al., 1996).

Given the prevalence and consequences of depression for individuals across their lifetime, identifying correlates and predictors of depression could guide the development of interventions targeting such variables. One factor that has been linked with depression in adolescents is religiosity (Pearce, Little, \& Perez, 2003). Previous studies have revealed an inverse relation between religiosity and depression (for reviews see Dew, Daniel, Armstrong, Goldston, Triplett, \& Koenig, 2008; Koenig, McCullough, \& Larson, 2001; Smith, McCullough, $\&$ Poll, 2003). In a meta-analysis of 147 studies, Smith and colleagues (2003) found an average effect size of $r=-.096$. The vast majority of these studies have been conducted with adults ( $n=$ 137), however; far fewer studies ( $n=10)$ have examined the link between religion and depression in adolescents. 
A better understanding of the relation between religion and depression in adolescents is needed for several reasons. First, religiosity is of considerable importance to many American adolescents. A recent national survey on religion revealed that $82 \%$ of American youth ages 13 to 17 report that their religious faith is at least 'somewhat important' in their daily life, $75 \%$ pray alone at least weekly, $71 \%$ feel 'somewhat close' to 'extremely close' to God, and $40 \%$ attend worship weekly or more often, (Smith \& Lundquist Denton, 2005).

Second, adolescence is the time when religious questioning and challenging of childhood assumptions increase (Hunsberger, Pratt, \& Pancer, 2002, Levenson, Aldwin, \& D’Mello, 2005). Such examination can lead to the transformation of childhood intuitive belief systems into the abstract beliefs of adulthood (Park, 2005). Third, as part of the broader process of identity development and self-evaluation typical of adolescence, teens begin to examine their religious identity and beliefs in an effort to reconcile and consolidate their identity and sense of self (Erikson, 1980; Marcia, 1991). Given the centrality of religion in the lives of many adolescents and the variety of developmental challenges that occur during this age period, adolescence has been called a time of "spiritual awakening," during which the study of the role of religion may be particularly important (Groeschel, 1983; King \& Boyatzis, 2004).

\section{Religious orientation}

Definitions of 'religiosity' have differed across studies. Horowitz and Garber (2003) measured religious attendance and the importance of religion for adolescents. Miller and colleagues added religious denomination (Miller, Warner, Wickramaratne, \& Weissman, 1997), institutional conservatism (i.e., relative fundamentalism of religious denomination), personal conservatism (i.e., the belief that the "sacred scriptures of your religion are the words of God and are completely without any mistakes," being a "Born-Again" Christian), and frequency of prayer 
(Miller \& Gur, 2002). Religious orientation also has been a focus of various studies and represents one of the most prominent frameworks in the study of religion to date (Allport \& Ross, 1967; Hill, 2005; Milevsky \& Levitt, 2004).

Religious orientation can be divided into intrinsic and extrinsic categories. Intrinsic religious orientation describes individuals who "find their master motive in religion." That is, for these individuals, religion is a primary motivator with "ultimate significance" and "all other needs are brought into harmony with the religious beliefs and prescriptions" (Allport \& Ross, 1967, p. 434). In contrast, extrinsic religious orientation describes individuals who are "disposed to use religion for their own ends." (Allport \& Ross, 1967, p. 434). For these individuals, religion may be useful by providing "security and solace, sociability and distraction, [and] status and selfjustification" (p. 434).

A recent study of adults found a different relation between extrinsic and intrinsic religious orientation and depression. Smith et al. (2003) reported that whereas intrinsic religious orientation was inversely related to depression (effect size $r=-.175$ ), extrinsic religious orientation correlated positively with depression (effect size $r=.155$ ). To date, only one study has examined the association between intrinsic and extrinsic religious orientation and depression in adolescents (Milevsky \& Levitt, 2004). This cross-sectional study of students in grades 6 through 8 found an inverse relation between intrinsic religiosity and depressive symptoms and no significant relation between extrinsic religiosity and depressive symptoms; this latter finding is in contrast to what has been found in adults (Dew, Daniel, Armstrong et al., 2008; Smith et al., 2003). For some youth, parental pressure to attend religious services is a stronger motivation to become involved in religious activities than is any internal drive (Benson, Roehlkepartain, \& Rude, 2003; Pearce et al., 2003). Thus, the distinction between extrinsic and intrinsic religious 
orientation might be especially salient for adolescents and may provide a framework from which to understand the role of religiosity in their lives.

\section{James and Wells' (2003) cognitive-behavioral framework}

What might explain the different relation of intrinsic versus extrinsic religious orientation to depression? James and Wells (2003) suggested that a religious framework provides individuals with a general cognitive-behavioral model from which to interpret negative life events. For individuals who are deeply committed to their religion (i.e., are intrinsically oriented), religious explanations of negative life events are likely to be accepted because they provide an understanding of these stressful events. For less committed individuals (i.e., extrinsically religious oriented), however, explanations of negative life events offered by religion will not provide certainty or clear understanding of these events and might cause even further questions (James \& Wells, 2003). Therefore, intrinsic religious orientation may prevent the development of depression, especially when individuals are confronted with negative life events. This effect has been referred to as the buffer hypothesis (Cohen \& Wills, 1985).

On the other hand, extrinsic religious orientation may not be associated with depression or might even increase the risk of developing depression when individuals are confronted with negative life events. Of note, however, is that the 'main effect hypothesis' (i.e., religious orientation reduces the risk of developing depression independent of negative life events) and the buffering hypothesis are not mutually exclusive. As Smith et al. (2003) indicated, intrinsic religious orientation may be related to significantly lower levels of depressive symptoms for all individuals, but the association may become even stronger under conditions of stressful events.

Inherent in James and Wells' (2003) framework is a unidirectional effect of religious orientation on depression; that is, religious orientation, either extrinsic or intrinsic, may be 
related to the subsequent development of depression. Less clear, however, is whether the reverse is true; that is, that depression predicts the subsequent development of religious orientation. To date, only a few prospective studies have tested the direction of the association between religious orientation and depression in adolescents. One longitudinal study found evidence for a bidirectional relation between depression and religiosity in adolescents (Horowitz \& Garber, 2003) when religious attendance was the measure of religiosity. They reported a relation between depression and reduced attendance/religiosity, which mirrors other evidence suggesting the relationship between religious behavior and mental health is independent of religious orientation (James \& Wells, 2003). Thus, depression and attendance in religious activities may be expected, then, to display a bidirectional association, whereas the potential temporal association between depression and religious orientation is less clear. Accordingly, one purpose of the current shortterm longitudinal study was to examine the prospective and directional relations between both intrinsic and extrinsic religious orientation and depressive symptoms in adolescents. Negative life events and cognitions

Finally, most studies examining the relation between religious orientation and depression have not considered other variables (e.g., stress, negative cognitions) previously shown to be related to depression. One exception is the cross-sectional study of young adults by Maltby and Day (2000) who controlled for several variables including causal attributions of negative life events, optimism, self-esteem, problem-focused coping, neuroticism, and trait anxiety. Maltby and Day (2000) also separated extrinsic orientation into two measures: extrinsic-personal (religion viewed as a source of comfort) and extrinsic-social (religion viewed as a social gain). All three forms of religious orientation (intrinsic and two forms of extrinsic) were found to account for unique variance in depressive symptoms above and beyond the control variables. 
Given the lack of such studies in general, and particularly in adolescents, another goal of our prospective study was to examine the relation between religious orientation (intrinsic and two forms of extrinsic) and depression in youth, controlling for two known correlates of depression -negative life events and a pessimistic cognitive style.

Negative life events are a significant source of stress for adolescents (for a review see Dumont \& Provost, 1999). As many as $60 \%$ to $70 \%$ of youth with depression have experienced one or more "severe" negative life event(s) in the year prior to the onset of their depression (Birmaher et al., 1996), and negative life events account for approximately $10 \%$ of the variance in depression (e.g., Christensen, 1981). Intrinsic religious orientation also has been hypothesized to prevent the development of depression especially in the context of negative life events (James \& Wells, 2003). Further, T. Smith et al. (2003) showed in their meta-analysis of studies of both adults and adolescents, that the association between religiosity and depression was stronger for individuals undergoing major life events. Thus, not only might negative life events be a risk factor for depression, but they also may interact with religiosity, to affect depression.

A pessimistic cognitive style is a central element of the hopelessness theory of depression (Abramson, Alloy, \& Metalsky, 1989). According to Abramson and colleagues, the development and maintenance of depression results from biased information processing as reflected by a pessimistic cognitive style. Cognitive style outlined in the hopelessness model includes (a) causal attributions of negative life events (i.e., internal, stable, global), (b) inferred consequences of negative life events, and (c) inferred self-characteristics (e.g., self, own value, abilities, personality) following negative life events. External influences such as negative life events can activate a pessimistic cognitive style, then leading to depression. Evidence supporting this model has been found in studies of both adolescents (e.g., Abela, McGirr, \& Skitch, 2007) and adults 
(e.g., Alloy et al., 2004). In addition to the association between cognitive style and depression, Maltby and Day (2000) found a significant positive correlation between attributional style and extrinsic-personal religious orientation in their cross-sectional study of college students. Moreover, religious orientation and attributional style were somewhat collinear, as each predicted more variance in depression when entered singly in separate regression models than when entered both together. Therefore, in current study cognitive style was controlled when testing the association between religious orientation and depression.

\section{Hypotheses}

Our short-term, longitudinal study examined the degree of association between extrinsicpersonal, extrinsic-social, and intrinsic religious orientation and their interactions with negative life events with depressive symptoms in adolescents, controlling for the effect of cognitive style. Additionally, the direction of the relation between religious orientation and depression was examined. Based on the cognitive-behavioral framework of James and Wells (2003) and previous studies (e.g., Maltby \& Day, 2000; Milevsky \& Levitt, 2004), we hypothesized that, after controlling for prior depression and cognitive style, intrinsic religious orientation, particularly in interaction with negative life events, would be inversely associated with depression. We further hypothesized that both extrinsic orientations would not be associated positively with depression but might be associated either negatively (Maltby \& Day, 2000; Smith T. B. et al., 2003) or not at all (Milevsky \& Levitt, 2004), given the conflicting findings in the literature. Finally, we expected that religious orientation would predict depressive symptoms rather than the reverse.

\section{Method}

\section{Participants}


Participants were 273 students (mean age $=15.29$ years; $S D=0.68$ ) in Wellness classes at a high school in the mid-south of the United States; $65.2 \%$ of the sample was female. The sample was 74.4\% Caucasian, $14.7 \%$ African-American, 4.8\% Latino, 0.7\% Asian/Pacific Islander, 0.4\% Native American, 4.4\% Mixed Heritage, and $0.7 \%$ Other. County data indicated that $29 \%$ of the students were eligible for free or reduced-price lunch programs; census data indicated that the school serves communities characterized as predominantly working to middle class.

\section{Measures}

Depressive symptoms were measured with the Children's Depression Inventory (CDI; Kovacs, 1981), the most widely used self-report measure of depressive symptoms in children (Kazdin, 1981). The 26 items measure cognitive, affective, and behavioral symptoms of depression (the suicide item was excluded at the request of school personnel). Each item lists three statements, scored 0 through 2 , in order of increasing symptom severity. Respondents rate each item as to how much they have experienced the symptom in the past two weeks. The CDI has been found to differentiate between normal and clinically depressed youth (Carey, Faulstich, Gresham, Ruggiero, \& Enyart, 1987). In the current sample, internal consistency of the CDI was $\alpha=.94$.

Religious orientation was measured with the Age Universal Intrinsic-Extrinsic Scale (AUIES), developed originally by Allport and Ross (1967), and later modified by other researchers who used simplified language so as to measure intrinsic and extrinsic orientation towards religion for children and adolescents (Gorsuch \& Venable, 1983), and who changed the original 5-point Likert response format to a 3-point scale (Maltby \& Lewis, 1996). In the version of the AUIES used in the current study (Maltby, 1999), participants responded to each of the 12 items about their religious views and practices by indicating "Yes" (1), "Not Sure" (2), or "No"(3) as to whether it was true for them. Higher scores represent lower religious (intrinsic or 
extrinsic) orientation. The twelve items are divided into three scales: (a) Intrinsic (e.g., "I enjoy reading about my religion.”), (b) Extrinsic-Personal (e.g., "I pray mainly to gain relief and protection."), and (c) Extrinsic-Social (e.g., "I go to church because it helps me to make friends."). Gorsuch and Venable (1983) demonstrated that the measure was both reliable and valid and could be used with children as young as fifth grade. In addition, multiple studies have demonstrated that the AUIES is a reliable measure in religious and non-religious samples including adolescents and adults (Maltby \& Lewis, 1996; Maltby, 1999; Maltby, Houran, Lange, Ashe, \& McCutcheon, 2002; Milesvsky \& Levitt, 2004). In the current study, the AUIES yielded an internal consistency of $\alpha=.72$ for the intrinsic scale, $\alpha=.75$ for the extrinsicpersonal scale, and $\alpha=.63$ for the extrinsic-social scale.

Life events were measured with the Life Event Checklist (LEC, Masten, Neemann, Andenas, 1994), which consists of 50 items describing chronic or discrete negative life events that may happen to adolescents. Respondents answer "yes" or "no" regarding whether or not the event has happened in their lives within the past 4 months. Endorsed items are summed; total scores can range from 0 to 50, with higher scores representing more life events.

The Adolescent Cognitive Style Questionnaire (ACSQ; Hankin \& Abramson, 2002) was used to assess negative cognitive style. The ACSQ consists of 12 hypothetical negative scenarios relevant for adolescents (e.g. "You receive a bad grade on a test."). For each scenario, adolescents are asked to write down one possible cause for the event. They then rate on a 7-point Likert scale the degree to which their stated cause of the event (i.e., attribution) is (a) internal vs. external, (b) stable vs. unstable, or (c) global vs. specific. These three attribution dimensions are summed across the items and situations to calculate a composite score. Adolescents also rate the likelihood that further negative consequences will result from this event. Finally, respondents 
rate the degree to which the occurrence of the event signifies that they are flawed as a person. Questions measuring the three different dimensions of causal attributions are summed across the items and situations to calculate a composite score. Items measuring inferences for consequences and for the self, respectively, are added across the situations to comprise two additional scores. In the current sample internal consistencies were $\alpha=.94$ for attributions, $\alpha=.93$ for inferred consequences, and $\alpha=.94$ for inferences about the self.

\section{Procedure}

Letters describing the study were sent to parents of all students in Wellness classes. Students who received parental consent were invited to participate. Measures were administered in groups during school twice within four months by trained undergraduate and graduate psychology students. The study was approved by the Institutional Review Board for the protection of human subjects.

\section{Statistical analyses}

Separate stepwise hierarchical regression models were fit using SPSS version 17 for each type of religious orientation (i.e., intrinsic, extrinsic-personal, extrinsic-social) to test whether each religious orientation predicted self-reported depressive symptoms four months after the first assessment. In Step 1, prior depressive symptoms (CDI), total life events (LEC), and negative cognitions (ACSQ) were entered as control variables; the religious orientation scores (AUIES intrinsic, extrinsic personal, extrinsic social) were entered in Step 2 (in 3 separate analyses). In Step 3, the interactions between the religious orientation scores (AUIES intrinsic, extrinsic personal, extrinsic social) and negative life events (LEC) were entered (in 3 separate analyses). The depression score (CDI) at the four-month follow-up was the dependent variable. 
To test the reverse relations (whether depressive symptoms predicted religious orientation four months after the initial assessment), separate regression models were fit for each AUIES scale (intrinsic, extrinsic-personal, extrinsic-social religious orientation). LEC and ACSQ as well as the appropriate AUIES score assessed at Time 1 were entered as the Step 1 control variables. At Step 2, baseline CDI scores were entered as the predictor. AUIES scores at the four-month follow-up (Time 2) were the dependent variables. In addition to these regressions analyses, all models were refit three times: (1) controlling for sex and age; (2) with the ACSQ composite score separated into three scales (internal-external, stable-unstable, global-specific); (3) and controlling for sex and age, and using ACSQ subscales instead of a composite score. All analyses revealed the same results. Therefore, only the basic regressions are reported here.

A total of six regression models were fit. Accordingly, the significance levels of these analyses were Bonferroni adjusted; only p-values smaller than .008 were considered significant in the current analyses. With a sample size of 273 and $\alpha$ pre-determined at .05 , power in these analyses was adequate (>.80) to detect effect sizes of $\mathrm{f}^{2}=.056$ (Cohen, 1998).

Results

\section{Correlations among Depression, Religious Orientation, Life events, and Cognitive Style}

Table 1 presents the means, standard deviations, and estimated correlation coefficients between self-reported depressive symptoms and religious orientation subscales at both time points as well as with Time 1 measures of negative life events and cognitive style. The 4-month test-retest reliabilities of all three religious orientation scales were higher than the correlations with the CDI. These findings were not surprising, given the episodic nature of depression and the general stability of religious orientation. As expected, Time 1 and Time 2 CDI correlated significantly with LEC and ACSQ scales measured at Time 1. Interestingly, at both time points, 
extrinsic-personal religious orientation was more highly correlated with intrinsic orientation than with external-social religious orientation.

\section{Religious Orientation as a Predictor of Depressive Symptoms}

Intrinsic Religious Orientation. Controlling for Time 1 CDI, LEC, and ACSQ scores ( $\mathrm{R}^{2}$ $=.324, p \leq .001)$, Time 1 intrinsic religious orientation significantly predicted CDI scores four months later $\left(\mathrm{R}^{2}\right.$ change $\left.=.025, p=.002\right)$. That is, higher intrinsic religious orientation, as represented by lower scores on the AUIES, was significantly associated with lower levels of depressive symptoms, controlling for all else in the model. The intrinsic religious orientation at Time 1 main effect accounted for $2.5 \%$ of the variance in CDI scores four months later, controlling for all else in the model. The addition of the Time 1 intrinsic religious orientation by negative life events interaction term, however, did not add significantly to the prediction of CDI scores $\left(\mathrm{R}^{2}\right.$ change $\left.>.001, p=.858\right)$ (see Table 2$)$.

Extrinsic-Social Religious Orientation. Controlling for Time 1 CDI, LEC, and ACSQ scores $\left(\mathrm{R}^{2}=.327, p \leq .001\right)$, Time 1 extrinsic-social religious orientation did not significantly predict CDI scores four months later $\left(\mathrm{R}^{2}\right.$ change $\left.=.009, p=.061\right)$. The addition of the Time 1 extrinsic-social religious orientation by negative life events interaction term did not add significantly to the prediction of CDI scores $\left(\mathrm{R}^{2}\right.$ change $\left.>.001, p=.867\right)$.

Extrinsic-Personal Religious Orientation. Controlling for Time 1 CDI, LEC, and ACSQ scores $\left(\mathrm{R}^{2}=.327, p \leq .001\right)$, Time 1 extrinsic-personal religious orientation did not significantly predict CDI scores four months later $\left(\mathrm{R}^{2}\right.$ change $\left.=.008, p=.080\right)$. The addition of the Time 1 extrinsic-personal religious orientation by negative life events interaction effect did not significantly predict CDI scores $\left(\mathrm{R}^{2}\right.$ change $\left.>.001, p=.959\right)$. Depressive Symptoms as a Predictor of Religious Orientation 
Intrinsic Religious Orientation. Controlling for Time 1 AUIES intrinsic religious orientation, LEC, and ACSQ scores $\left(\mathrm{R}^{2}=.459, p \leq .001\right)$, Time 1 CDI did not significantly predict intrinsic orientation scores four months later $\left(\mathrm{R}^{2}\right.$ change $\left.=.006, p=.091\right)$ (see Table 3 ).

Extrinsic-Social Religious Orientation. After controlling for Time 1 AUIES extrinsicpersonal religious orientation, LEC, and ACSQ scores $\left(\mathrm{R}^{2}=.294, p \leq .001\right)$, Time 1 CDI did not significantly predict extrinsic-personal orientation scores four months later $\left(\mathrm{R}^{2}\right.$ change $=.011, p$ $=.049$, unadjusted $)($ see Table 4$)$.

Extrinsic-Personal Religious Orientation. After controlling for Time 1 AUIES extrinsicsocial religious orientation, LEC, and ACSQ scores $\left(\mathrm{R}^{2}=.218, p \leq .001\right)$, Time 1 CDI did not significantly predict extrinsic-social orientation scores four months later $\left(\mathrm{R}^{2}\right.$ change $=.016, p=$ .025 , unadjusted) (see Table 5).

\section{Discussion}

Consistent with the cognitive-behavioral framework (James \& Wells, 2003), previous research (Dew, Daniel, Armstrong et al., 2008; Koenig et al., 2001; Smith et al., 2003), and our hypothesis, higher intrinsic religious orientation significantly predicted lower depressive symptoms in adolescents four months later, after controlling for cognitive style and Time 1 depressive symptoms. Neither extrinsic-personal nor extrinsic-social religious orientation significantly predicted depressive symptoms at the four-month follow-up, controlling for cognitive style and Time 1 depressive symptoms. In addition, the interaction between each religious orientation subscale and negative life events did not significantly predict depressive symptoms. Moreover, depressive symptoms did not significantly predict religious orientation four months later, controlling for cognitive style, negative life events, and prior religious orientation. In contrast to previous research, we conducted conservative tests of the relation 
between religious orientation and depressive symptoms by controlling for other well-established predictors of depressive symptoms (i.e., cognitive style). Finally, no bi-directional relations were found between depression and religious orientation.

That more intrinsic religious orientation predicts lower depressive symptoms after controlling for cognitive style highlights the importance of intrinsic religious orientation as a possible protective factor in relation to depression in youth. This finding replicates Maltby and Day’s (2000) results with young adults, demonstrating the generalizability of this association across different age groups. Indeed, an intrinsic religious orientation might help reduce the likelihood of depression in adolescents.

Consistent with the results of the study by Milevsky and Levitt (2004) with young adolescents, the current study found no significant relation between extrinsic religious orientation and later depressive symptoms when controlling for prior depression and cognitions. In contrast, studies with adults (e.g., Maltby \& Day, 2000) have revealed significant relations between these variables. The association between religiosity and depression in adolescents is only about half to a third as strong as in adult populations (Smith et al., 2003). Although the cognitive-behavioral framework (James \& Wells, 2003) does not provide an explanation for differences between adolescent and adult samples, developmental models might. For example, within any adolescent sample, individuals may be at different stages of psychosocial (Erikson, 1980; Marcia, 1991) and/or of faith and religious development (Fowler \& Dell, 2004). Because the association between extrinsic religious orientation and depressive symptoms might be masked by the variance attributable to such stage differences, finding a relation between religious orientation and depression might be difficult. 
Additionally, adolescence is a time when individuals begin to define their own identity (Schwartz, 2008) and when friendships play an increasingly important role in this self-evolution (Williams, Connolly, \& Segal, 2001). Some adolescents may become involved in religious activities to meet or be with friends (extrinsic-social orientation) rather than for reasons based on an intrinsically-religious orientation. This normative social-seeking behavior during adolescence may diminish the association between extrinsic-social religious orientation and depression in youth.

Beyond adolescence, young adults' interests become more varied and their individuality begins to play a central role in their identity development (Erikson, 1980; Santrock, 2007). Accordingly, individuals might be expected to develop a more intrinsic religious orientation over time while simultaneously decreasing their extrinsic-social religious orientation, as friends become a less important reason for church attendance and internal, personal reasons take precedence. In addition, adolescents may begin to find friends outside of their religiously-based community, thereby decreasing their extrinsic-social religious orientation, particularly if those friends do not participate in the same religious activities. For individuals who follow this pathway, high extrinsic-social orientation in adulthood might be considered aberrant and indicate one's reliance on external sources of support versus internal resources in adulthood, or a lack of social skills that leads to the inability to develop new and varied friendships. Low social skills and an external locus of control may contribute to both a high extrinsic-social religious orientation and to depression (Presson \& Benassi, 1996; Rudolph \& Clark, 2001). Accordingly, a high extrinsic-social religious orientation might be expected to be related to higher levels of depressive symptoms during adulthood, consistent with the findings from adult studies (e.g., 
Maltby \& Day, 2000). One shortcoming of this hypothesis, however, is that it does not explain the lack of a significant prediction of depression by extrinsic-personal religious orientation.

A developmental systems model might explain the lack of significant associations between both extrinsic religious orientations and depression in adolescents. Attending religious activities, even without internal motivation, may offer a form of social integration (Regnerius \& Elder, 2003). Accorting to Roehlkepartain (2005), religious communities provide adolescents with the opportunity to build meaningful, positive relationships with adults and peers. Such an opportunity may be especially important during adolescence given the importance of social support by friends and other non-family members for coping, resilience, and well-being (King \& Roesner, 2006). Studies have shown that social support gained by attending religious activities is a strong predictor of depressive symptoms in adolescents (Miller \& Gur, 2002; Pearce, Little, \& Perez, 2003; Wagener, Furrow, King, Leffert, \& Benson, 2003). Thus, the negative effects of both extrinsic religious orientations (typically found in adults) might be buffered by the positive effects of social support adolescents acquire from their religious communities. To test this hypothesis, future studies should evaluate the simultaneous effects of religious orientation, social relationships, and social support provided by a religious community on depressive symptoms in adolescents to determine if both extrinsic religious orientations might predict depression in adolescents only when the effects of social relationships and social support are controlled. Contrary to the predictions of the cognitive-behavioral framework (James \& Wells, 2003), the interaction between religious orientation and negative life events did not predict depressive symptoms 4-months later. One possible explanation is that the measured negative life events were not chronic or severe enough to be truly stressful for the adolescents. Another possible explanation is that most of the adolescents were experiencing a similar level of 
normative stress related to the transition from middle- to high-school (Roeser, Eccles, \& Strobel, 1998). The vast majority of students in the Wellness classes from which the adolescents were recruited for this study were $9^{\text {th }}$ grader. Thus, the level of negative life events might not have varied sufficiently in the current sample. Future studies should assess particular types of stressful events, particularly school-related daily hassles (Roesser et al., 1998).

A final interesting result is the high correlation between intrinsic and extrinsic-personal religious orientation compared to the correlation between both extrinsic orientations. While the absolute amount of correlations between the three AUIES varies widely between studies with adults, this pattern is unpresidented (Maltby, 1999, 2002; Maltby et al., 1999; Maltby \& Day, 2000). Nevertheless, it needs to be considered that a recent study testing the factor structure of the AUIES in adolescents only could not extract the extrinsic-personal scale. Instead, many extrinsic-personal items loaded on the intrinsic scale (Banister \& Pössel, 2009). This might be mirrored by the relatively high correlations between intrinsic and extrinsic-personal religious orientation in our study. Nevertheless, the high correlation between intrinsic and extrinsicpersonal orientation seem not to have influenced the main results of our study as the association between intrinsic religious orientation and depressive symptoms are different from the associations of both extrinsic orientations with depression. Furthermore, both extrinsic orientations are associated with depressive symptoms in a similar way, independent of their correlation with depression.

Strengths of the current study included the use of an adolescent sample, controlling for other variables such as cognitive style previously shown to be related to adolescent depressive symptoms, testing the possible moderating role of religious orientation on the relation between 
stress and depressive symptoms, and the longitudinal design that allowed us to examine the temporal and directional relations between religious orientation and depressive symptoms.

Limitations of this study highlight directions for future research. First, the study was implemented in only one high-school in the southeastern United States. These results may not generalize to adolescents in other geographic locations. Second, only self-report measures were used, which might have resulted in an overestimation of the associations due to shared method variance. The magnitude of this overestimation seems limited, however, given the lack of a significant predictive relation between extrinsic religious orientation and depression. Third, the cognitive-behavioral framework of James and Wells (2003) does not provide a theoretical basis for the time span between both time points. Thus, the selection of time span between both time points was not theory-driven in our study. It is unclear whether the associations between religious orientation in general and the lack of bidirectional relationships in particular might be different when using a longer or shorter time span between time points. Support for the generalizability of our findings comes from Horowitz and Garber (2003). Studying the association between depression and self-rated importance of religiosity across several years in a similar population, these authors found the same unidirectional association as that found in the current study. Nevertheless, bidirectional relations between religious orientation and depression might occur in time spans shorter than four months. Future research is necessary to evaluate the relationships in shorter time spans. Forth, although significant, the amount of variance of depression predicted by intrinsic religious orientation was small $(2.5 \%)$. Other aspects of religiosity that might predict more variance should be investigated. In addition to interpersonal relationships and social support provided by members of the religious community, religious behaviors such as praying also may be important. Maltby, Lewis, and Day (1999) compared a 
number of religiosity measures (religious orientation, religious coping, and religious behaviors like church attendance and personal prayer) in terms of their prediction of unique variance in subjective well-being in adults, and found that frequency of personal prayer was the best predictor of better mental health in general and of depression in particular. In addition, strength and maturity of religious faith including both belief and behavioral elements (Benson, Donahue, \& Erickson, 1993; Plante \& Boccaccini, 1997; Salsman \& Carlson, 2005) are other aspects of religiosity that should be explored in relation to depression. For example, maturity of faith was found to be associated not only with socially responsible behaviour (Benson, Donahue, \& Erickson, 1993) but also with depression in university students (Salsman \& Carlson, 2005). Future studies should examine the unique relations of various aspects of religiosity to adolescent depression while mutually controlling for their overlapping effects. Fifth, as noted by Dew, Daniel, Goldston, and Koenig (2008), the quantity and quality of the association between religion and depression might be different in community versus clinically depressed samples. A replication of the current study within an adolescent clinical population would address this concern. Finally, without the conservative Bonferroni adjustment employed in these analyses, depressive symptoms did predict extrinsic-social and extrinsic-personal religious orientation four months later, controlling for measures at the first assessment. The use of larger samples would increase power to detect small but significant relations among these constructs.

In summary, after controlling for initial levels of depressive symptoms and cognitive style, higher intrinsic religious orientation significantly predicted lower self-reported depressive symptoms four months later, but not the reverse. In contrast, controlling for these same variables, extrinsic religious orientation was not significantly associated with depressive symptoms. Contrary to expectation, religious orientation did not significantly buffer the relation between 
negative life events and depressive symptoms. Future studies should measure normative schoolrelated daily hassles when testing the cognitive-behavioral framework (James \& Wells, 2003) in adolescents. Finally, future research should explore what factors explain differences in the relation between religious orientation and depression across development. 


\section{References}

Abela, J. R. Z., McGirr, A., \& Skitch, S. A. (2007). Depressogenic inferential styles, negative events, and depressive symptoms in youth: An attempt to reconcile past inconsistent findings. Behaviour Research and Therapy, 45, 2397 - 2406.

Abramson, L.Y., Alloy, L.B., \& Metalsky, G.I. (1989). Hopelessness depression: a theory-based subtype of depression. Psychological Bulletin, 96, 358 - 372.

Alloy, L. B., Abramson, L. Y., Gibb, B. E., Crossfield, A. G., Pieracci, A. M., Spasojevic, J., \& Steinberg, J. A., (2004). Developmental antecedents of cognitive vulnerability to depression: review of findings from the Cognitive Vulnerability to Depression Project. Journal of Cognitive Psychotherapy: An International Quaterly, 18, 115 - 133.

Allport, G.W., \& Ross, J. M. (1967). Personal religious orientation and prejudice. Journal of Personality and Social Psychology, 6, 432-443.

Benson, P. L., Donahue, M. J., \& Erickson, J. A. (1993). The Faith Maturity Scale: conceptualization, measurement, and empirical validation. In M. L. Lynn \& d. O. Moberg (Eds.), Research in the social scientific study of religion (pp. 1 - 26). Greenwich: JAI Press.

Benson, P. L., Roehlkepartain, E. C., \& Rude, S. P. (2003). Spiritual development in childhood and adolescence: Toward a field of inquiry. Applied Developmental Science, 7, 204- 212.

Birmaher, B., Ryan, N. D., Williamson, D. E., Brent, D. A., Kaufman, J., Dahl, R. E., Perel, J., \& Nelson, B. (1996). Childhood and adolescent depression: A review of the past 10 years. Part I: Journal of the American Academy of Child and Adolescent Psychiatry, 35, 1427-1439. Carey, M.P., Faulstich, M.E., Gresham, F.M., Ruggiero, L., \& Enyart, P. (1987). Children's Depression Inventory: Construct and discriminant validity across clinical and non-referred (control) populations. Journal of Consulting and Clinical Psychology, 55, 755-761. 
Chatter, L.M. (2000). Religion and health: Public Health Research and Practice. Annual Review of Public Health, 21, 335-367.

Christensen, J. F. (1981). Assessment of stress: Environmental, intra-personal, and outcome issues. In P. McReynolds (Ed.), Advances in Psychological Assessment, Vol. 5. Palo Alto, CA: Science and Behavior.

Cohen, J. (1998). Statistical power analysis for the behavioral sciences. Hillside, NJ: Lawrence Erlbaum Associates.

Cohen, S. \& Wills, T. A. (1985). Stress, social support, and the buffering hypothesis. Psychological Bulletin, 98, $310-357$.

Costello, E. J., Foley, D. L., \& Angold, A. (2006). 10-year research update review: The epidemiology of child and adolescent psychiatric disorders: II. Developmental epidemiology. American Academy of Child and Adolescent Psychiatry, 45, 8-25.

Dew, R. E., Daniel, S. S., Armstrong, T. D., Goldston, D. B., Triplett, M. F., \& Koenig, H. G. (2008). Religion/spirituality and adolescent psychiatric symptoms: A review. Child Psychiatry and Human Development, 39, 381-398.

Dew, R. E., Daniel, S. S., Goldston, D. B., \& Koenig, H. G. (2008). Religion, spirituality, and depression in adolescent psychiatric outpatients. The Journal of Nervous and Mental Disease, 196, $247-251$.

Dumont, M. \& Provost, M. A. (1999). Resilience in adolescents: Protective role of social support, coping strategies, self-esteem and social activities on experience of stress and depression. Journal of Youth and Adolescence, 28, 343 - 363.

Erikson, E. H. (1980). Identity and the life cycle (2 ${ }^{\text {nd }}$ ed.). New York, NY: Norton. 
Fowler, J. W. \& Dell, M. L. (2004). Stages of faith and identity: Birth to teens. Child and Adolescent Psychiatric Clinics of North America, 13, 17-33.

Frye, A. A. \& Goodman, S. H. (2000). Which social problem-solving components buffer depression in adolescent girls? Cognitive Therapy and Research, 24, $637-650$.

Gorsuch, R.L., \& Venable, G.D. (1983). Development of an “Age Universal” I-E scale. Journal for the Scientific Study of Religion, 22, 181-187.

Greenberg, P. E., Kessler, R. C., Birnbaum, H. G., Leong, S. A., Lowe, S. W., Berglund, P. A., \& Corey-Lisle, P. K. (2003). The economic burden of depression in the United States: how did it change between 1990 and 2000? Journal of Clinical Psychiatry, 64, 1465-1475.

Groeschel, B. J. (1983). Spiritual Passage: The psychology of spiritual development. New York, NY: Crossroads.

Hackney, C.H., \& Sanders, G.S. (2003). Religiosity and mental health: A meta-analysis of recent studies. Journal for the Scientific Study of Religion, 42, 43-55.

Hankin, B. L. \& Abramson, L. Y. (2002). Measuring cognitive vulnerability to depression in adolescence: Reliability, validity, and gender differences. Journal of Clinical Child and Adolescent Psychology, 31, 491-504.

Hill, P. C. (2005). Measurement in the psychology of religion and spirituality. Current status and evaluation. In R. F. Paloutzian \& C. L. Park (Eds.), Handbook of the psychology of religion and spirituality (pp. 43 - 61). New York, NY: Guilford.

Horowitz, J. L. \& Garber, J. (2003). Relation of intelligence and religiosity to depressive disorders in offspring of depressed and nondepressed mothers. Journal of the American Academy of Child and Adolescent Psychiatry, 42, 578-586. 
Hunsberger, B., Pratt, M. \& Pancer, S. M. (2002). A longitudinal study of religious doubts in high school and beyond: Relationships, stability, and searching for answers. Journal for the Scientific Study of Religion, 41, 255 - 266.

Kasen, S., Cohen, P., Skodol, A. E., Johnson, J. G., Smailes, E. M. \& Brook, J. S. (2001). Childhood depression and adult personality disorder. Alternative pathways of continuity. Archives of General Psychiatry, 58, 231-236.

King, P. E. \& Boyatzis, C. J. (2004). Exploring adolescent spiritual and religious development: current and future theoretical and empirical perspectives. Applied Developmental Science, 8, $2-6$.

King, P. E. \& Roeser, R. W. (2009). Religion and spirituality in adolescent development. In R. M. Lerner \& L. Steinberg (Eds.), Handbook of Adolescent Psychology, Vol. 1: Individual Bases of Adolescent Development (pp. 435 - 478). Hoboken, NJ: John Wiley.

Koenig, H.G. \& D.B. Larson. (2001). Religion and mental health: Evidence for an association. International Review of Psychiatry, 13, 67-78.

Koenig, H. G., McCullough, M. E., \& Larson, D. B. (2001). Handbook of religion and health. New York: Oxford University Press.

Kovacs, M. (1981). Rating scales to assess depression in school-aged children. Acta Paedopsychiatrica, 46, 305-315.

Levenson, M. R., Aldwin, C. M., \& D’Mello, M. (2005). Religious development from adolescence to middle adulthood. In R. F. Paloutzian \& C. L. Park (Eds.), The psychology of religion and spirituality (pp. 144 - 161). New York, NY: Guilford Press. 
Maltby, J. (1999). The internal structure of a derived, revised, and amended measure of the religious orientation scale: the 'Age Universal' I_E Scale-12. Social Behavior and Personality, 27, 407-412.

Maltby, J. (2002). The Age Universal I-E Scale-12 and orientation toward religion: confirmatory factor analysis. The Journal of Psychology, 136, 555 - 560.

Maltby, J. \& Day, L. (2000). Depressive symptoms and religious orientation: Examining the relationship between religiosity and depression within the context of other correlates of depression. Personality and Individual Differences, 28, 383-393.

Maltby, J., Houran, J., Lange, R., Ashe, D., \& McCutcheon, L. E. (2002). Thou shalt worship no other gods - unless they are celecrities: the relationship between celecrity worship and religious orientation. Personality and Individual Differences, 32, $1152-1172$.

Maltby, J. \& Lewis, C. A. (1996). Measuring intrinsic and extrinsic orientation toward religion: amendments for its use among religious and non-religious samples. Personality and Individual Differences, 21, 937 - 946.

Maltby, J., Lewis, C. A., \& Day, L. (1999). Religious orientation and psychological well-being: The role of the frequency of personal prayer. British Journal of Health Psychology, 4, 363 378.

Marcia, J. E. (1991). Identity and self-development. In R. M. Lerner, A. C. Petersen, \& E. J. Brooks-Gunn (Eds.), Encyclopedia of adolescence (Vol. 1, pp. 527 - 531). New York, NY: Garland.

Masten, A. S., Neemann, J., \& Andenas, S. (1994). Life events and adjustment in adolescents: the significance of event independence, desirability, and chronicity. Journal of Research on Adolescence, 4, 71-97. 
McCullough, M. E. \& Larson, D. B. (1999b). Prayer. In W. R. Miller (Ed.), Integrating Spirituality into Treatment. Resources for Practicioner. Washington, DC: American Psychological Association.

Milevsky, A. \& Levitt, M.J. (2004). Intrinsic and extrinsic religiosity in preadolescence and adolescence: Effect on psychological adjustment. Mental Health, Religion \& Culture, 7, 307321.

Miller, L. \& Gur, M. (2002). Religiosity, depression, and physical maturation in adolescent girls. Journal of the American Academy of Child and Adolescent Psychiatry, 41, 206 - 214.

Miller, L., Warner, V., Wickramaratne, P., \& Weissman, M. (1997). Religiosity and depression: Ten-year follow-up of depressed mothers and offspring. Journal of the American Academy of Child and Adolescent Psychiatry, 36, 1416 - 1425.

Park, C. L. (2005). Religion and meaning. In R. F. Paloutzian \& C. L. Park (Eds.), Handbook of the Psychology of Religion (pp. 295 - 314). New York, NY: Guilford Press.

Pearce, J.M., Little, T.D., \& Perez, J.E. (2003). Religiousness and depressive symptoms among adolescents. Journal of Clinical Child and Adolescent Psychology, 32, 267-276.

Presson, P. K. \& Benassi, V. A. (1996). Locus of control orientation and depressive symptomatology: a meta-analysis. Journal of Social Behavior \& Personality, 11, 201 - 212.

Regnerus, M. \& Elder, G. H. Jr. (2003). Staying on track in school: Religious influences in highand low-risk settings. Journal for the Scientific Study of Religion, 42, 633 - 649.

Roehlkepartain, E. C. (2005). Congregations: Unexamined crucibles for spiritual development. In E. C. Roehlkepartain, P. E. King, L. M. Wagner, \& P. L. Benson (Eds.), The handbook of spiritual development in childhood and adolescence (pp. 324 - 336). Thousand Oaks, CA: Sage. 
Roeser, R. W., Eccles, J. S., \& Strobel, K. R. (1998). Linking the study of schooling and mental health: Selected issues and empirical illustrations at the level of the individual. Educational Psychologist, 33, 153-176.

Rudolph, K. D. \& Clark, A. G. (2001). Conceptions of Relationships in Children with Depressive and Aggressive Symptoms: Social- cognitive Distortion or Reality? Journal of Abnormal Child Psychology 29, 41-56.

Salsman, J. M. \& Carlson, C. R. (2005). Religious orientation, mature faith, and psychological distress: elements of positive and negative associations. Journal for the Scientif Study of Religion, 44, $201-209$.

Santrock, J. W. (2007). A topical approach to life-span development $\left(4^{\text {th }}\right.$ ed.). Boston, MA: McGraw-Hill.

Schwartz, S. J. (2008). Self and identity in early adolescence: Some reflections and an introduction to the special issue. The Journal of Early Adolescence, 28, 5-15.

Smith, C. \& Lundquist Denton, M. (2005). Soul Searching. The religious and spiritual lives of American teenagers. New York, NY: Oxford University.

Smith, T. B., McCullough, M. E., \& Poll, J. (2003). Religiousness and depression: Evidence for a main effect and the moderating influence of stressful life events. Psychological Bulletin, 129, 614-636.

Ustun, T. B., Ayuso-Mateos, J. L., Chatterji, S., Mathers, C., \& Murray, C. J. (2004). Global burden of depressive disorders in the year 2000. British Journal of Psychiatry, 184, 386-392.

Wagener, L. M., Furrow, J. L., King, E. P., Leffert, N., \& Benson, P. L. (2003). Religious involvement and developmental resources in youth. Review of Religious Research, 44, 271 284. 
Weissman, M. M., Wolk, S., Goldstein, R. B., Moreau, D., Adams, P., Greenwald, S., Klier, C. M., Ryan, N. D., Dahl, R. E., \& Wickramaratne, P. (1999). Depressed adolescents grow up. JAMA, 281, 1707-1713.

Wenger, J.L. (2004). The automatic activation of religious concepts: Implications for religious orientations. The International Journal for the Psychology of Religion, 14, 109-203.

Williams, S., Connolly, J., \& Segal, Z. (2001). Intimacy in relationships and cognitive vulnerability to depression in adolescent girls. Cognitive Therapy and Research, 25, 477-496. 
Table 1. Correlations among Depressive Symptoms, Religious Orientation, Life Events, and Cognitive style $(n=273)$.

\begin{tabular}{|c|c|c|c|c|c|c|c|c|c|c|c|c|c|c|}
\hline & 1 & 2 & 3 & 4 & 5 & 6 & 7 & 8 & 9 & 10 & 11 & 12 & mean & SD \\
\hline \multicolumn{15}{|l|}{ Inventory (CDI) } \\
\hline 2. T2 Children' Depression & & -- & $.26^{* *}$ & $.31 * *$ & $.19 * *$ & $.16^{* *}$ & .07 & -.03 & $.51 * *$ & $.22 * *$ & $.26 * *$ & $.30 * *$ & 9.49 & 8.72 \\
\hline 3. T1 Intrinsic religious & & & -- & $.65^{* *}$ & $.62 * *$ & $.45^{* *}$ & $.23 * *$ & .10 & .10 & $.17 * *$ & $.13^{*}$ & $.20 * *$ & 1.75 & 0.55 \\
\hline \multicolumn{15}{|l|}{ beliefs } \\
\hline 4. T2 Intrinsic religious & & & & -- & $.52 * *$ & $.58 * *$ & $.20 * *$ & $.17 * *$ & $.16^{*}$ & $.24 * *$ & $.17 * *$ & $.17 * *$ & 1.75 & 0.59 \\
\hline \multicolumn{15}{|l|}{ religious beliefs } \\
\hline 6. T2 Extrinsic-personal & & & & & & -- & $.21 * *$ & $.23 * *$ & .12 & $.23 * *$ & $.20 * *$ & $.22 * *$ & 1.80 & -.61 \\
\hline \multicolumn{15}{|l|}{ religious beliefs } \\
\hline 7. T1 Extrinsic-social & & & & & & & -- & $.43 * *$ & -.04 & .07 & -.07 & -.001 & 2.12 & 0.61 \\
\hline
\end{tabular}


Religious orientation and depression 32

religious beliefs

8. T2 Extrinsic-social

$--\quad-.08$

$-.08$

.12

$-.06 \quad-.04$

2.24

0.61

religious beliefs

9. T1 Life Events Checklist

$\begin{array}{llllll}-- & .16 * & .25 * * & .24 * * & 9.64 & 7.84\end{array}$

(LEC)

10. T1 ACSQ Attributions

$\begin{array}{lllll}-- & .66 * * & .68 * * & 111.45 & 40.82\end{array}$

11. T1 ACSQ Consequences

$\begin{array}{llll}-- & .83 * * & 30.98 & 15.19\end{array}$

12. T1 ACSQ Self

$--\quad 28.65 \quad 15.61$

Note. ${ }^{*} p<.05 ; * * p<.01 ; \mathrm{ACSQ}=$ Adolescent Cognitive Style Questionnaire; Consequences = negative inferences about consequence Self $=$ negative inferences about self; $\mathrm{T} 1=$ Time $1 ; \mathrm{T} 2=$ Time 2 
Table 2. Separate Stepwise Fitted Hierarchical Regression Models for each Type of Religious Orientation at Time 1 as Predictor and Time 2 Depressive Symptoms (4 months later) as Outcome, Controlling for Time 1 Depressive Symptoms, Life Events, and Cognitive Style

B $\quad$ SE B $\quad \beta$

Step 1

T1 Children's Depression Inventory

$.16 \quad .04 \quad .22 * *$

T1 Life Events Checklist

$.44 \quad .06 \quad .39 * *$

T1 ACSQ Attributions

$\begin{array}{lll}.02 & .02 & .11\end{array}$

T1 ACSQ Consequences

$\begin{array}{lll}-.07 & .06 & -.11\end{array}$

T1 ACSQ Self

$\begin{array}{lll}.09 & .06 \quad .15\end{array}$

Step 2 for Intrinsic Religious Orientation

T1 Children's Depression Inventory

T1 Life Events Checklist

T1 ACSQ Attributions

T1 ACSQ Consequences

T1 ACSQ Self

T1 Intrinsic religious orientation

Step 3 for Intrinsic Religious Orientation

T1 Children's Depression Inventory

T1 Life Events Checklist

T1 ACSQ Attributions

T1 ACSQ Consequences

$\begin{array}{ccc}.14 & .04 & .20^{* *} \\ .44 & .06 & .39 * * \\ .02 & .02 & .08 \\ -.05 & .06 & -.08 \\ .07 & .06 & .12\end{array}$

$2.61 \quad .85 \quad .16^{* *}$

$\begin{array}{lll}.14 & .04 & .20 * *\end{array}$

$.47 \quad .19 \quad .42 *$

$\begin{array}{lll}.02 & .02 & .08\end{array}$

$\begin{array}{lll}-.05 & .06 & -.08\end{array}$ 


\begin{tabular}{|c|c|c|c|}
\hline T1 ACSQ Self & .07 & .06 & .12 \\
\hline T1 Intrinsic religious orientation & 2.79 & 1.28 & .17 \\
\hline $\mathrm{T} 1$ Intrinsic religious orientation by $\mathrm{T} 1 \mathrm{Life}$ & -.02 & .10 & -.03 \\
\hline \multicolumn{4}{|l|}{ Events Checklist } \\
\hline \multicolumn{4}{|l|}{ Step 2 for Extrinsic-Social Religious Orientation } \\
\hline T1 Children's Depression Inventory & .16 & .04 & $.23 * *$ \\
\hline T1 Life Events Checklist & .45 & .06 & $.40 * *$ \\
\hline T1 ACSQ Attributions & .02 & .02 & .09 \\
\hline T1 ACSQ Consequences & -.05 & .06 & -.09 \\
\hline T1 ACSQ Self & .08 & .06 & .14 \\
\hline T1 Extrinsic-social religious orientation & 1.34 & .76 & .09 \\
\hline \multicolumn{4}{|l|}{ Step 3 for Extrinsic-social Religious Orientation } \\
\hline T1 Children's Depression Inventory & .16 & .04 & $.23 * *$ \\
\hline T1 Life Events Checklist & .44 & .20 & $.39 *$ \\
\hline T1 ACSQ Attributions & .02 & .02 & .09 \\
\hline T1 ACSQ Consequences & -.05 & .06 & -.09 \\
\hline T1 ACSQ Self & .08 & .06 & .14 \\
\hline T1 Extrinsic-social religious orientation & 1.18 & 1.18 & .09 \\
\hline T1 Extrinsic-social religious orientation by & .09 & .09 & .01 \\
\hline \multicolumn{4}{|l|}{ T1 Life Events Checklist } \\
\hline \multicolumn{4}{|l|}{ Step 2 for Extrinsic-Personal Religious Orientation } \\
\hline T1 Children's Depression Inventory & .15 & .04 & $.21 * *$ \\
\hline T1 Life Events Checklist & .44 & .06 & $.39 * *$ \\
\hline
\end{tabular}


Religious orientation and depression 35

\begin{tabular}{lccc}
\hline T1 ACSQ Attributions & .02 & .02 & .10 \\
T1 ACSQ Consequences & -.06 & .06 & -.11 \\
T1 ACSQ Self & .08 & .06 & .13 \\
T1 Extrinsic-personal religious orientation & 1.35 & .72 & .10 \\
Step 3 for Extrinsic-personal Religious Orientation & & & \\
T1 Children's Depression Inventory & .15 & .04 & .21 \\
T1 Life Events Checklist & .47 & .18 & .42 \\
T1 ACSQ Attributions & .02 & .02 & .11 \\
T1 ACSQ Consequences & -.06 & .06 & -.11 \\
T1 ACSQ Self & .08 & .06 & .13 \\
T1 Extrinsic-personal religious orientation & 1.49 & 1.13 & .11 \\
T1 Extrinsic-personal religious orientation & -.02 & .09 & -.03 \\
$\quad$ by T1 Life Events Checklist & & &
\end{tabular}

Note. $* p<.008 ; * * p<.004 ; \mathrm{B}=$ unstandardized beta coefficient; $\mathrm{SE} \mathrm{B}=$ standard error of the unstandardized coefficient; $\beta=$ standardized beta coefficient; T1 = Time 1; ACSQ $=$ Adolescent Cognitive Style Questionnaire. Consequences $=$ negative inferences for consequences scale of ACSQ; Self = negative inferences about the self 
Table 3. Stepwise Fitted Hierarchical Regression Model for Intrinsic Religious

Orientation at Time 2 as Predicted by Time 1 Depressive Symptoms, Controlling for

Time 1 Intrinsic Religious Orientation, Life Events, and Cognitive Style

\begin{tabular}{llll}
\hline & B & SE B & $\beta$ \\
\hline Step 1 & & & \\
\hline
\end{tabular}

Step 1

T1 Intrinsic religious orientation

$.69 \quad .05 \quad .64 * *$

T1 Life Events Checklist

$.006 \quad .004 \quad .09$

T1 ACSQ Attributions

$.002 \quad .001 \quad .16+$

T1 ACSQ Consequences

$.004 \quad .003 \quad .10$

T1 ACSQ Self

$\begin{array}{lll}-.006 & .003 & -.17\end{array}$

Step 2

T1 Intrinsic religious orientation .70

$.05 \quad .65^{* *}$

T1 Life Events Checklist $.008 \quad .004 \quad .11$

T1 ACSQ Attributions $.002 \quad .001 \quad .13$

T1 ACSQ Consequences $.005 \quad .003 \quad .13$

T1 ACSQ Self $\begin{array}{lll}-.006 & .003 \quad-.15\end{array}$

T1 Children's Depression Inventory $\begin{array}{lll}-.004 & .003 & -.09\end{array}$

Note. $+p<.016 ; * p<.008 ; * * p<.004 ; \mathrm{B}=$ unstandardized beta coefficient; $\mathrm{SE} \mathrm{B}=$ standard error of the unstandardized coefficient; $\beta=$ standardized beta coefficient; $\mathrm{T} 1=$ Time 1; LEC = Life Event Checklist; ACSQ = Adolescent Cognitive Style Questionnaire Consequences $=$ negative inferences for consequences scale of ACSQ; Self $=$ negative inferences about the self 
Table 4. Stepwise Fitted Hierarchical Regression Model for Extrinsic-Personal Religious Orientation at Time 2 Predicted by Time 1 Depressive Symptoms, Controlling for Time 1 Extrinsic-Personal Religious Orientation, Life Events, and Cognitive Style

\begin{tabular}{lllll}
\hline & B & SE B & $\beta$ \\
\hline
\end{tabular}

Step 1

T1 Extrinsic-Personal religious orientation .49 $.05 \quad .51 * *$

T1 Life Events Checklist

$.003 \quad .004 \quad .04$

T1 ACSQ Attributions

$.002 \quad .001 \quad .15$

T1 ACSQ Consequences

$.000 \quad .004 \quad-.006$

T1 ACSQ Self

$.001 \quad .004 \quad .03$

Step 2

T1 Extrinsic-Personal religious orientation

$\begin{array}{lll}.50 & .05 & .53 * * \\ .006 & .004 & .07 \\ .002 & .001 & .12 \\ .001 & .004 & .02 \\ .002 & .004 & .06 \\ -.006 & .003 & -.12\end{array}$

Note. $+p<.016 ; * p<.008 ; * * p<.004 ; \mathrm{B}=$ unstandardized beta coefficient; $\mathrm{SE} \mathrm{B}=$ standard error of the unstandardized coefficient; $\beta=$ standardized beta coefficient; $\mathrm{T} 1=$ Time 1; LEC = Life Event Checklist; ACSQ = Adolescent Cognitive Style Questionnaire. Consequences $=$ negative inferences for consequences scale of ACSQ; Self $=$ negative inferences about the self 
Table 5. Stepwise Fitted Hierarchical Regression Model for Extrinsic-Social Religious Orientation at Time 2 Predicted by Time 1 Depressive Symptoms, Controlling for Time 1 Extrinsic-Social Religious Orientation, Life Events, and Cognitive Style

\begin{tabular}{llll}
\hline & B & SE B & $\beta$ \\
\hline
\end{tabular}

Step 1

T1 Extrinsic-Social religious orientation

$\begin{array}{ccc}.41 & .06 & .41 * * \\ -.004 & .005 & -.06 \\ .003 & .001 & .22^{*} \\ -.002 & .004 & -.06 \\ -.005 & .004 & -.12\end{array}$

T1 ACSQ Self

Step 2

T1 Extrinsic-Social religious orientation

$\begin{array}{ccc}.42 & .06 & .42 * * \\ -.008 & .005 & -.10 \\ .004 & .001 & .26 * * \\ -.004 & .004 & -.09 \\ -.006 & .004 & -.15 \\ .007 & .003 & .15\end{array}$

T1 Life Events Checklist

T1 ACSQ Attributions

T1 ACSQ Consequences

T1 ACSQ Self

T1 Children's Depression Inventory

.007

Note. $+p<.016 ; * p<.008 ; * * p<.004 ; \mathrm{B}=$ unstandardized beta coefficient; $\mathrm{SE} \mathrm{B}=$ standard error of the unstandardized coefficient; $\beta=$ standardized beta coefficient; $\mathrm{T} 1=$ Time 1; LEC = Life Event Checklist; ACSQ = Adolescent Cognitive Style Questionnaire Consequences $=$ negative inferences for consequences scale of ACSQ; Self $=$ negative inferences about the self 